\title{
O Turismo Cultural e a Problemática da Capacidade de Carga do Património: Estudo da dimensão social do caso da Catedral do Porto
}

\author{
Raquel Sousa Marques
}

\begin{abstract}
Resumo: O turismo é o principal motor do desenvolvimento local e regional, porém, o seu avanço pode gerar uma pressão excessiva sobre os recursos de um destino, alterando negativamente as condições sociais e económicas e a qualidade de vida da população residente. $\mathrm{A}$ crescente expansão do turismo, devido ao elevado fluxo de visitantes, suscita a necessidade de geri-lo de acordo com os parâmetros da sustentabilidade, isto é, com uma utilização responsável dos recursos explorados, de forma a garantir a sua conservação e transmissão para as gerações futuras. Nesse sentido, é grande a preocupação com o controle dos impactos negativos sobre os recursos patrimoniais gerados pelo grande fluxo de visitantes. Neste artigo apresentamos o estudo da dimensão social da Sé do Porto, visto ser um dos monumentos mais visitados da cidade.
\end{abstract}

Palavras-chave: património cultural, turismo cultural, monumento, capacidade de carga, Catedral do Porto

\section{El Turismo Cultural y la Problemática de la Capacidad de Carga del Patrimonio: Estudio de la dimensión social del caso de la Catedral de Oporto}

Resumen: El turismo es el principal motor del desarrollo local y regional, sin embargo, su avance puede generar una presión desmedida sobre los recursos de un destino, modificando negativamente las condiciones sociales, económicas y la calidad de vida de la población residente. La creciente expansión del turismo debido al alto flujo de visitantes, incita a la necesidad de gestionarlo de acuerdo con los parámetros de sostenibilidad, es decir, desde el punto de vista del uso responsable de los recursos que se exploran, con el objetivo de garantizar su conservación y transmisión a las generaciones futuras. En este sentido, existe una enorme preocupación concerniente al control de los impactos negativos sobre los recursos patrimoniales generados por la gran afluencia de visitantes. En este artículo presentamos el estudio de la dimensión social del caso de la Catedral de Oporto, ya que es uno de los monumentos más visitados de la ciudad.

Palabras clave: patrimonio cultural, turismo cultural, monumento, capacidad de carga, Catedral de Oporto

\section{The Cultural Tourism and the Problems of the Carrying Capacity of Heritage: Study of the social dimension of the Porto Cathedral case}

\begin{abstract}
Tourism is the main stimulator of local and regional development; however, its progress can provoke excessive pressure on the destination's resources, negatively modifying the social and the economic conditions and the life quality of the resident population. The increasing expansion of tourism due to the high flow of visitors, encourages the need to manage it according to sustainability parameters, that is, from the point of view of the responsible use of the resources that are exploited, aiming to guarantee their preservation and transmission to future generations. In this sense, huge concern arises regarding the control of negative impacts on heritage resources endangered by the high influx of visitors. This article, we present the social dimension study of the Porto Cathedral case, since it is one of the most visited monuments in the city.
\end{abstract}

Keywords: cultural heritage, cultural tourism, monument, carrying capacity, Porto Cathedral 


\section{Introdução}

O turismo, no geral, tem um forte impacto podendo resultar em grande quantidade de benefícios para as comunidades locais e, portanto, pode constituir-se como um fator de desenvolvimento. Segundo CeballosLascuráin (1996), conhecer e compreender os impactos ambientais que o turismo cultural e o turismo natureza poderão ter sobre os recursos existentes, são pré-requisitos fundamentais para definir a capacidade de carga turística de um local. Assim, conhecer os limites do local para o desenvolvimento do turismo, permite antecipar os níveis de saturação dos locais turísticos e aplicar estratégias de gestão adequadas (UNWTO e UNEP 2005).

De acordo com a Organização Mundial de Turismo (OMT) a capacidade de carga turística define-se como "o número máximo de pessoas que uma determinada área pode suportar, sem que haja alteração no meio físico, sem reduzir a satisfação dos visitantes e sem que se produza efeitos adversos sobre a comunidade recetora, a economia ou cultura local" (Oliveira 2013: 25)

"Los espacios patrimoniales, en tanto que recursos sobre los que se sustentan algunas de las prácticas asociadas al turismo cultural (visita de museos y monumentos, paseos por los cascos históricos...), han visto por tanto aumentar de manera también considerable su afluencia turística. Aunque ese crecimiento no es extensivo al total de recursos turístico-culturales de base patrimonial que se encuentran acondicionados para la visita pública, sí que existen problemas de sobrecarga turística que afectan en determinados momentos a los espacios y recursos más demandados" (Hernández e Vaquero 2012: 254).

Neste sentido, surge uma enorme preocupação relativamente ao controlo dos impactos negativos nos recursos patrimoniais gerados pela elevada afluência de visitantes e, consequentemente, manifesta-se a necessidade de realizar estudos de capacidade de carga dos recursos patrimoniais.

Verificamos que o conceito de capacidade de carga é bastante discutido na literatura estrangeira e, que não é uma ideia muito recente, muito pelo contrário. Nos Estados Unidos da América este conceito tem vindo a ser debatido desde os anos 60 do século XX (Bonilla e Bonilla 2008). Contudo, a aplicação deste conceito na gestão de destinos turísticos europeus é bastante escassa, refletindo-se em Portugal.

A crescente pressão das atividades turísticas sobre os recursos patrimoniais, despoletou na Organização Mundial de Turismo e outras entidades responsáveis pelo planeamento e gestão deste sector, que avaliassem a capacidade dos espaços onde se desenvolvessem atividades turísticas.

Neste artigo iremos apresentar o estudo da dimensão social do caso da Sé do Porto, um dos principais e mais antigos monumentos portugueses. Em 1910, a Sé do Porto foi classificada como Monumento Nacional e, em 1996, foi reconhecida pela UNESCO como integrada no Património Mundial do Centro Histórico do Porto, Ponte Luiz I e Mosteiro da Serra do Pilar exaltando ainda mais a sua importância cultural. Face à importância deste monumento e ao aumento exponencial do turismo em Portugal e, por conseguinte, na região norte do país, sentiu-se a necessidade de desenvolver um estudo que contribuísse para a conservação e salvaguarda da Sé do Porto.

A nossa investigação baseou-se em três questões principais, às quais pretendemos dar resposta, sendo as seguintes: Diariamente, quantas pessoas podem visitar a Sé do Porto, garantindo as mínimas condições de conservação do património? Quantas pessoas podem ser acomodadas ao mesmo tempo dentro do complexo monumental? Quais são as condições e equipamentos para as visitas públicas?

Este estudo teve três objetivos principais, sendo os seguintes: contribuir para a definição do conceito de capacidade de carga, determinar a capacidade de carga da Sé do Porto e aferir a qualidade da experiência, os níveis de conforto e a segurança dos visitantes.

De forma geral e de modo a dar resposta aos objetivos definidos, será adotada uma metodologia de carater misto, combinando técnicas quantitativas e qualitativas. Para a realização desta investigação pretendeu-se identificar e gerir referências de modo a permitir o desenvolvimento de uma revisão sistemática e crítica da literatura, relativamente ao conceito de capacidade de carga, procurando recolher informação que permitisse o estabelecimento de uma definição e a sua aplicação em recursos patrimoniais. Face à escassez de bibliografia específica em Portugal, foi necessário recorrer à consulta de bibliografia estrangeira, na qual encontramos uma panóplia de estudos sobre este tema. Em paralelo a essa recolha, foi estabelecido contacto com o Cabido Portucalense de modo a obter detalhes relativos à qualidade da visita e experiência dos visitantes, recorrendo a questionários e a visitas de campo. As técnicas utilizadas para obtenção de informação foram os questionários e a observação participante. Após a recolha de dados procedemos à análise dos mesmos através de procedimentos estatísticos e a uma organização de informações e anotações que foram recolhidas in situ. A observação permitiu identificar determinados aspetos que se revelaram cruciais para a nossa investigação.

\section{O conceito de Capacidade de Carga}

Revela-se de extrema importância conhecer os limites de um recurso para a sua exploração turística, ou seja, conhecer a sua capacidade de carga. O progresso do 
conceito de capacidade de carga tenciona dar resposta à problemática da saturação. Assim, este conceito parte do princípio de que há um limite máximo de carga, a partir do qual os ecossistemas revelam-se incapazes para regressar à sua condição de equilíbrio.

O termo capacidade indica a hipótese de conter ou acomodar num determinado espaço. Todavia, as suas origens estão relacionadas com a gestão da fauna em áreas naturais, tendo como objetivo determinar o número máximo de animais que podem ser mantidos num determinado lugar sem causar danos ao fornecimento de alimento e solo, procurando manter o equilíbrio entre a vida animal e vegetal (Bonilla e Bonilla 2008: 133). Como refere Bonilla e Bonilla (2008: 134): "Los antecedentes de la capacidad de carga en el turismo sustentable los podemos extraer del interés mostrado por las instituciones que gestionan los espacios naturales protegidos en Estados Unidos". Assim, os primeiros estudos sobre a capacidade de carga foram realizados em 1960, nos Estados Unidos da América por geógrafos do Serviço Florestal Americano, sendo que, o conceito foi elaborado para "para calcular el número de personas que pueden usar un área recreativa natural sin destruir sus características ecológicas esenciales" (Álvarez 2010: 225).

Os diversos estudos de capacidade de carga turística têm como objetivo colocar em prática o conceito de sustentabilidade, ou seja, como o Relatório Bruntland define um "modelo de desarrollo que permite satisfacer nuestras necesidades actuales sin comprometer la capacidad de las generaciones futuras para satisfacer las suyas" (Dû 2005: 30).

Inúmeros investigadores do turismo têm usado o conceito para se referir ao "número máximo de turistas que puede albergar un área de destino" (Lorente 2001: 12). Contudo, este conceito revela-se bastante complexo, uma vez que levanta bastantes controvérsias, quer na sua definição quer na sua aplicação.

As primeiras aplicações da capacidade de carga para gestão de parques e áreas naturais, revelaram que o foco inicial estava assente na relação entre o uso do visitante e as condições ambientais. Deste modo, o aumento do número de visitantes provocava maior impacto ambiental, medido pela destruição da vegetação, compactação do solo e variáveis relacionadas.

“En las décadas de 1960 y 1970, se desarrolló un sistema para establecer límites al número de visitantes de los parques, monumentos o áreas protegidas, con el fin de proteger los recursos naturales y culturales y determinar el punto en el cual comienzan los impactos negativos. El concepto fue criticado por cuanto la realidad demostraba que muchos de los impactos causados por los visitantes no necesariamente estaban relacionados con el número de los mismos" (Álvarez 2010: 225).
Assim, revela-se fundamental uma abordagem mais adaptada de forma a incluir as recomendações em estruturas de planeamento existentes. Assim, o conceito foi introduzido em formas de planeamento estratégico, nomeadamente nos Estados Unidos da América, Austrália, Canadá e América Latina.

“El nuevo modelo del concepto de capacidad de carga está basado en un mejor entendimiento de las relaciones entre el número de visitantes y el impacto que éstos causan ... [no se trata sólo de fijar un número límite de visitantes], claramente, no hay un número mágico. Los modelos actuales de manejo de visitantes suponen establecer metas y objetivos, formulando indicadores y monitoreando resultados" (Álvarez 2010: 225).

Desta forma, a capacidade de carga surge como um conceito mais maleável e dinâmico que pode ser ajustado às especificidades do sítio, possibilitando uma compreensão e orientação das mudanças e dos impactos provocados pelo turismo, propondo um modelo de gestão sustentável.

É evidente que, a capacidade de carga de um sítio não é apenas determinada por critérios espaciais e ambientais, depende do intuito para o qual foi concebido, implicando que não há uma única capacidade. Consequentemente, outros fatores começaram a ser considerados como a dimensão da experiência dos visitantes, realçando as dimensões sociais do conceito.

"As more people visit a park or related area, not only can the environmental resources of the area be affected, but the quality of the visitor experience as well. Again, the working hypothesis was that increasing numbers of visitors cause greater social impacts as measured by crowding and related variables. Thus, as applied to parks and related tourist attractions, carrying capacity has two components: environmental and social" (Manning, Wang, Valliere, Lawson, e Newman 2002: 389).

Uma das definições mais estimadas é proporcionada pela Organização Mundial do Turismo (OMT) que definiu a capacidade de carga como "the maximum number of people that may visit a tourist destination at the same time, without causing destruction of the physical, economic, socio-cultural environment and an unacceptable decrease in the quality if visitors" (UNWTO, 1981: 4). Segundo a OMT existem três tipos de capacidade de carga: a ecológica, a turística e a social.

"A capacidade de carga ecológica significa o nível a partir do qual ocorrem impactos ecológicos negativos e com consequências prejudiciais para o futuro; a capacidade de carga turística representa o nível a partir do qual as experiências dos visitantes se revelam insatisfatórias; a capacidade de carga social é o nível a partir do qual ocorrem mudanças sociais inaceitáveis no 
grupo de origem/comunidade local ou de acolhimento" (Brito 2017: 3).

A abordagem deste conceito por parte da OMT, não difere muito da de Pearce, visto que, a capacidade de carga estará excedida quando "as atividades turísticas estão saturadas - capacidade física -, o ambiente degradado - capacidade ambiental - e a convivência entre residentes e visitantes se torna desagradável - capacidade psicológica individual e coletiva" (Joaquim 1997: 72).

A capacidade de carga alude ao número máximo de visitantes que um determinado espaço/recurso/destino turístico pode abranger, quer dizer, o limite a partir do qual a exploração turística de um recurso/destino é insustentável. "La naturaleza de ese límite hace posible considerar diferentes dimensiones del concepto de capacidad de carga: capacidad de carga física, capacidad de carga ecológica, capacidad de carga social, capacidad de carga económica, ..." (Hernández e Vaquero 2012: 255). A capacidade de carga turística de cada lugar é definida através da dimensão do conceito, na qual varia em cada caso:

“Capacidad de carga ecológica en las Islas Galápagos o en los parques nacionales de Estados Unidos, capacidad de carga económica en el caso de la ciudad de Venecia, capacidad de carga física en relación a infraestructuras básicas en la Costa del Sol, capacidad de carga perceptual en las playas de la isla de Menorca o capacidad de carga social en la ciudad de Oxford" (Hernández e Vaquero 2012: 255).

A nível metodológico, este conceito foi desenvolvido segundo distintas abordagens. A nível ambiental, "las primeras definiciones sugerían que la capacidad de carga era el nivel de uso recreativo de un área natural protegida que aseguraba el mantenimiento de la calidad medioambiental y la calidad de la experiencia recreativa de los visitantes de los espacios naturales protegidos" (Hernández e Vaquero 2012: 256). Através do emprego do conceito a destinos turísticos, como ilhas, cidades, zonas costeiras, entre outros, as dimensões social e económica foram incluídas.

"Desde este enfoque, los indicadores de la capacidad de carga son los umbrales más allá de los cuales los flujos turísticos declinan porque los propios visitantes empiezan a juzgar sobrepasadas determinadas capacidades del espacio; definición estrechamente relacionada con el ciclo de vida de los destinos turísticos" (Hernández e Vaquero 2012: 256).

Segundo as perspetivas assentes na perceção do fenómeno turístico pela comunidade local, a capacidade de carga turística é determinada e perfilada como um método de análise que demarca os impactos inadequados que o turismo pode gerar e propõe a tomada de decisões. Por outras palavras, é um instrumento adequado para a gestão de visitantes e a avaliação dos impactos provocados pela presença humana em sítios patrimoniais e áreas protegidas.

Ao longo do tempo, podemos verificar que quando se trata de empregar o conceito de capacidade de carga em destinos turísticos, o destaque da investigação modificou da procura de limites numéricos para o desenvolvimento de quadros teórico-conceituais para o planeamento e gestão de espaços turísticos. Desta forma, a elaboração de modelos e metodologias amplas e flexíveis possibilitaram analisar os sítios de acordo com uma abordagem sistémica e integral, tendo como objetivo principal a sustentabilidade.

"Las metodologíasque seaplican al evaluarla capacidad de carga hacen posible, entre otras cosas, comprender los valores que definen los sitios patrimoniales y las áreas protegidas; detectar los conflictos, problemas y riesgos que les afectan; establecer los indicadores y estándares que permiten alcanzar condiciones óptimas; caracterizar y evaluar la visita; y definir las estrategias de manejo y monitoreo que aseguren la conservación de los sitios. La evaluación de la capacidad de carga es, por tanto, una herramienta de gran utilidad para detectar y monitorear el cambio, guiar la toma de decisiones y definir el uso sostenible de los sitios patrimoniales y áreas protegidas" (Álvarez 2010: 221-222).

Sempre que foram realizados trabalhos de conservação numa área protegida surge como necessidade conservar o património através do desenvolvimento de formas de avaliação e monitorização. Deste modo, "la evaluación y monitoreo periódicos permiten el seguimiento del estado de conservación de los sitios patrimoniales y las áreas protegidas, contar con la información necesaria para definir escenarios de manejo y conservación y tomar decisiones" (Álvarez 2010: 224).

Em conformidade com o que foi abordado na Convenção do Património de 1992, a UNESCO estabeleceu que a avaliação e a monitorização contínua são ferramentas imprescindíveis para garantir a conservação de valores e a importância dos sítios de importância global. Assim, cada país define conforme as suas necessidades as estratégias e metodologias a ser implementadas, como por exemplo, no continente americano, a avaliação da capacidade de carga é um dos instrumentos usados para avaliar e monitorizar o impacto da atividade turística nas áreas protegidas, zonas costeiras e sítios de interesse cultural.

Contudo, como podemos naturalmente perceber, este conceito exibe notáveis problemas de operacionalização, dado que se define diante de situações de saturação já existentes e revela-se árduo a previsão dos limites absolutos para cada espaço.

“Estes limiares de utilização só têm sido experimentos em zonas sujeitas a pressões muito elevadas, colocando 
problemas complexos de operacionalização. Para uma discussão mais substantiva coloca ainda duas questões adicionais: o problema da definição científica dos limites e a sua aceitabilidade social, implicando a inclusão das premissas culturais de aceitabilidade no processo científico e técnico da definição de limites" (Joaquim 1997: 72).

\section{O Estudo de caso da Sé do Porto}

A Sé do Porto é um dos monumentos portuenses mais visitados e, como tal, revela-se de extrema importância definir qual a sua capacidade de carga, tendo em vista diversos fatores, tais como: a qualidade da experiência, o conforto e a segurança dos visitantes, mas também a conservação e a salvaguarda do monumento.

O sector turístico assenta na existência e exploração de recursos - naturais, culturais e humanos-e pode provocar grandes transformações nos locais onde se desenvolve. Se, por um lado, é assumido como uma fonte de receitas e emprego, por outro, poderá representar uma ameaça para a estrutura e organização social existente, bem como para o património natural e cultural de que depende (Oliveira 2013). A consciencialização destes impactos do turismo revelou que era necessário conhecer os limites dos recursos patrimoniais para a sua exploração turística, ou seja, conhecer a sua capacidade de carga.

A Sé do Porto é um monumento de interesse histórico e cultural, constituindo um bem de atração turística. Logo, decidimos realizar um estudo que nos permitisse avaliar a capacidade de carga e analisar as condições das visitas que ocorrem no monumento, devido aos problemas de saturação já existentes em determinados locais.

A metodologia utilizada focou-se em três tipos de análise, tendo como base o modelo de avaliação da Catedral de Santiago de Compostela, que compreenderam o trabalho in situ: uma análise dos equipamentos para visitas públicas, uma análise do perfil e comportamento do visitante e uma análise do fluxo de visitantes. Também, incluiu dois cálculos, sendo necessário calcular a Capacidade de Carga Física (CCF) e a Capacidade de Carga Máxima (CCM).

Primeiramente, calculamos a capacidade de carga física que permitiu estimar o número máximo de pessoas que se podiam acomodar ao mesmo tempo na catedral, usando a relação entre o espaço de circulação disponível e o espaço mínimo necessário para uma pessoa se movimentar livremente dentro do complexo monumental. Embora, consideremos que não existe um número exato que determine o número máximo de pessoas que possam visitar ao mesmo tempo um espaço patrimonial das características da Sé do Porto, considerou-se que não seria aconselhável exceder as densidades de uso superiores a $2 \mathrm{~m} 2$ por pessoa, valor usado para o estudo de capacidade de carga da Catedral de Santiago de Compostela (Hernández e Vaquero 2012). O espaço de circulação disponível corresponde aproximadamente a $603 \mathrm{~m}^{2}$, sendo que podem ser acomodadas ao mesmo tempo dentro do complexo monumental, aproximadamente 302 pessoas.

Em seguida, calculamos a capacidade de carga máxima da Sé do Porto. O tempo médio de permanência foi estimado entre 30-40 minutos, com um horário de abertura pública de dez horas (9h00-19h00), o número máximo de pessoas que podem ser acomodadas dentro da Catedral nunca deve exceder 4523 visitantes diários. Neste sentido, devemos sempre ter em consideração o efeito cumulativo do impacto dos visitantes a nível diário, semanal, mensal e anual.

A utilização das diferentes portas existentes como rotas de entrada e saída de visitantes permitiu uma melhor gestão do fluxo de visitantes. Esta medida de gestão foi implementada em fevereiro de 2019 e permite uma melhor organização do espaço de circulação, visto que os visitantes dispersam mais facilmente e, consequentemente, permite a oração dos residentes que, outrora, não era possível porque entravam pela Igreja provocando imenso ruído. Atualmente, as duas entradas disponíveis são na antiga Casa do Cabido, onde está localizada a Bilheteira e a entrada da Galilé, apenas para grupos organizados, como por exemplo, escolas, Viking Cruises, entre outros.

A metodologia utilizada para recolha de informação do perfil e comportamento dos visitantes foram através de métodos quantitativos e qualitativos. A nível quantitativo realizaram-se contagens das entradas dos visitantes na Sé do Porto e, em termos qualitativos, analisou-se as características, comportamentos e diferenciou-se o tipo de visitantes através da sua motivação.

As contagens dos visitantes foram realizadas eletronicamente no período compreendido de 1 de julho a 18 de julho de 2019, tendo em consideração a distinção dos visitantes individuais e os grupos de visitantes. Esta distinção foi necessária para medir com precisão o impacto das visitas de grupo. Os parâmetros utilizados para os grupos organizados foram a composição, a duração da visita, o itinerário, os pontos de explicação, os pontos de interesse ou contemplação e as áreas de repouso. Essas informações foram obtidas através da monitorização e observação do comportamento dos visitantes, durante toda a visita, desde que o grupo entrou na catedral.

Pretendemos complementar a informação quantitativa das contagens com os resultados dos questionários, também aplicados no mesmo período, tendo como objetivo de identificar a motivação da visita, grau de satisfação dos visitantes, entre outros. Por fim, a observação permitiu identificar os locais de congestionamento espacial, os pontos de interesse ou 
contemplação, as áreas de repouso, o comportamento dos visitantes, o horário de maior afluência, entre outros.

\section{Discussão dos Resultados}

Os objetivos desta investigação são: contribuir para a definição do conceito de capacidade de carga; determinar a capacidade de carga da Sé do Porto e aferir a qualidade da experiência, com base nos níveis de conforto e de segurança dos visitantes. As técnicas de recolha de informação utilizadas foram os questionários e a observação participante.

O tema da capacidade de carga passou de uma questão menosprezada para um elemento-chave das investigações de turismo e da conservação do património cultural e natural. Este conceito passou por diversas etapas, desde a procura de números específicos até à abordagem da gestão fundamentada em expectativas sociais e experimentais.

Através das contagens das entradas dos visitantes na Sé do Porto, podemos comprovar que a capacidade de carga da Sé do Porto até ao momento não foi atingida [gráfico 1]. No entanto, devemos ter em consideração que, futuramente, será necessário analisar uma série parâmetros não quantificáveis, tais como o dióxido de carbono, o vapor de água, a poeira e o ambiente sonoro. Estes parâmetros são extremamente importantes para a capacidade de carga de um recurso turístico-cultural.

Adicionalmente, a realização dos questionários, resultou numa amostra de 100 questionários válidos em cinco idiomas diferentes: alemão, espanhol, francês, inglês e português. Do total dos inquiridos $63 \%$ pertenciam ao sexo feminino e $37 \%$ ao sexo masculino [gráfico 2], a faixa etária que se se destacou foi a de 25-54 anos [gráfico 3] e a maioria dos inquiridos visitaram a Sé do Porto em família. Obteve-se uma variedade significativa relativamente à nacionalidade dos inquiridos, cujo maior valor correspondeu à nacionalidade espanhola (29\%), seguidos

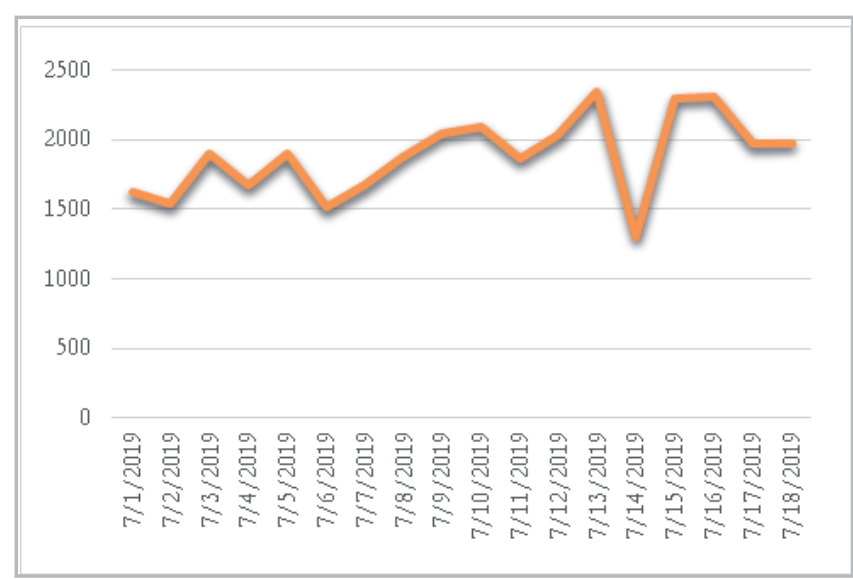

Gráfico 1.- Contagem de visitantes da Sé do Porto dos visitantes franceses (16\%), portugueses (10\%) e brasileiros (9\%). Os questionários foram respondidos por inquiridos de Alemanha, Bélgica, Estados Unidos da América, Grécia, Holanda, Índia, Inglaterra, Itália, Irlanda e Suíça. A principal motivação da visita foi a motivação patrimonial/cultural, correspondendo a $90 \%$ do total dos inquiridos [gráfico 4].

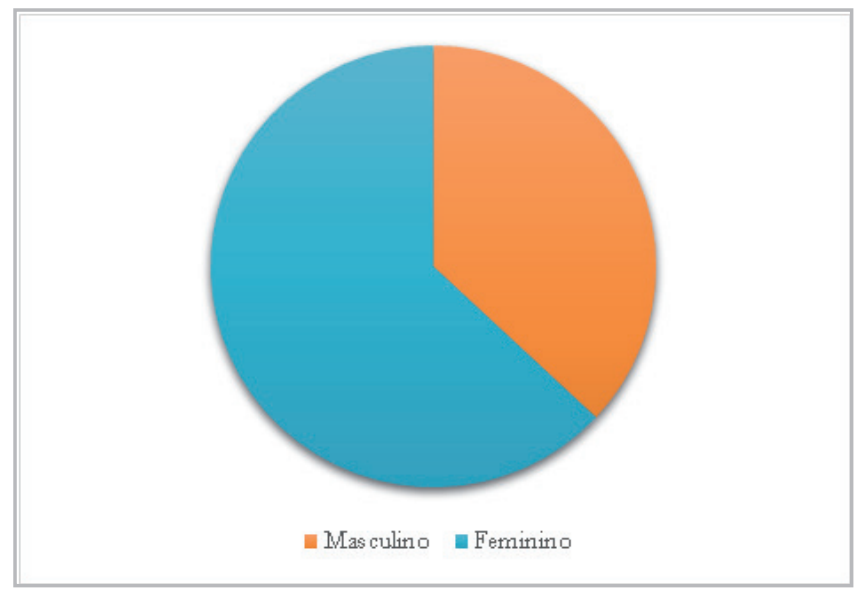

Gráfico 2.- Género dos visitantes

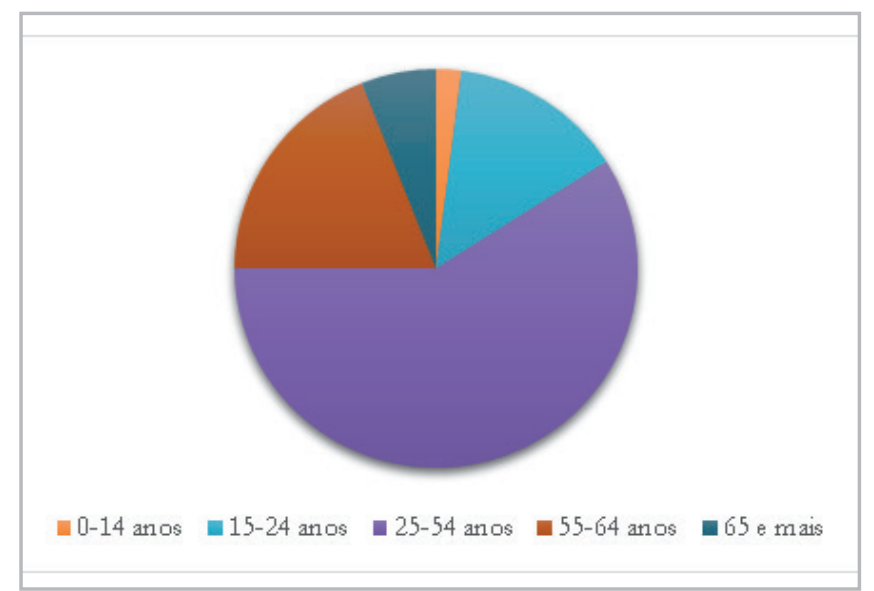

Gráfico 3.- Faixa etária dos visitantes

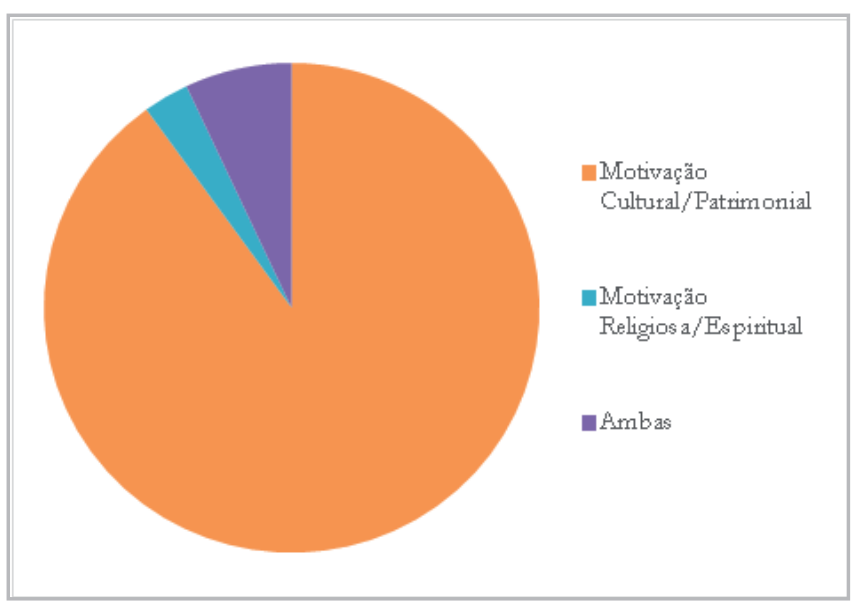

Gráfico 4.- Motivação da visita 
De acordo com os inquiridos, a Sé do Porto está bem conservada [gráfico 5], não existem nem problemas de sobrecarga e massificação turística, nem dificuldade em movimentar-se dentro do complexo monumental. No entanto, os inquiridos consideram necessário estabelecer limites ao aumento do turismo para não prejudicar as condições físicas do monumento e aplicar um sistema de controlo do fluxo de visitantes [gráfico 6]. Podemos verificar que a maioria dos inquiridos ficou muito satisfeito (93\%) ao visitar a Sé do Porto [gráfico 7].

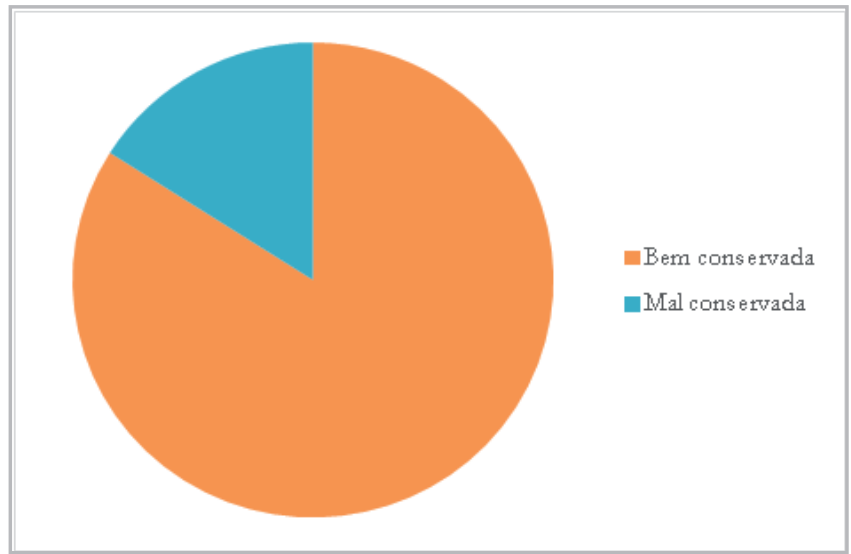

Gráfico 5.- Conservação da Sé do Porto

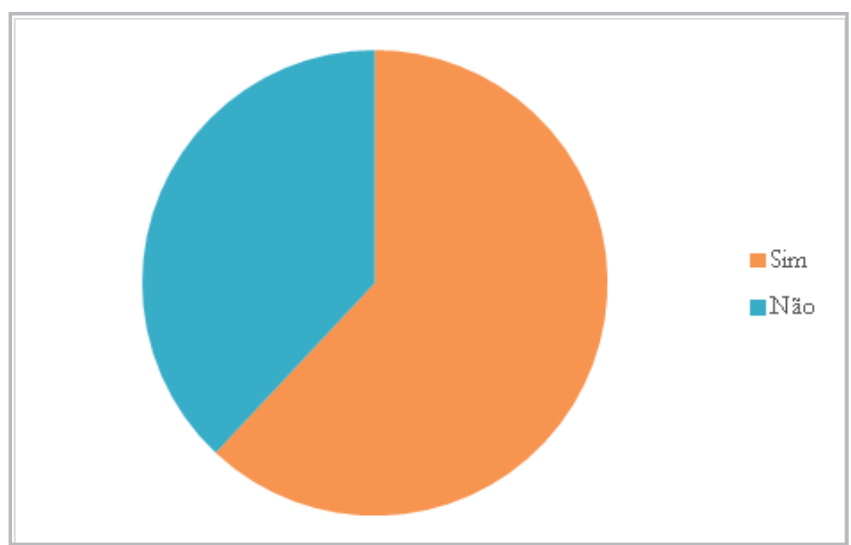

Gráfico 6.- Aplicação de um sistema de controlo do fluxo de visitantes

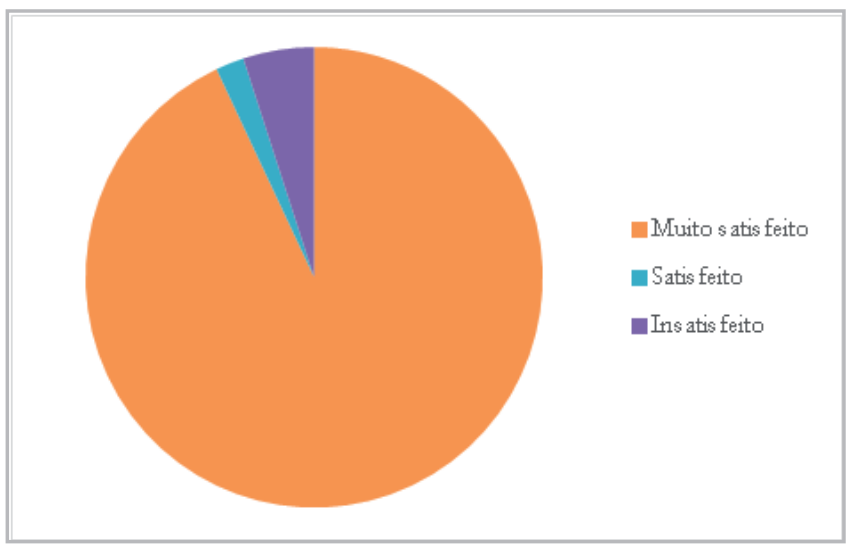

Gráfico 7.- Nível de satisfação da visita
A observação participante permitiu retirar as seguintes ilações, tanto dos visitantes individuais como dos grupos de visitantes:

- Os locais de congestionamento espacial são a Capela de São Vicente, a Capela São João Evangelista, a Sacristia e a Sala do Tesouro;

- Os pontos de interesse ou contemplação são o Claustro Gótico (cruzeiro medieval e azulejos), a Igreja (capela-mor, altar de prata da Capela do Santíssimo Sacramento e Altar da Nossa Senhora da Vandoma) e a Sacristia;

- Identificação de algumas ações de desrespeito pelo património por parte dos visitantes, como por exemplo: captação de fotografias com flash no interior da igreja, caminhar por cima das sepulturas escadas na rocha, utilizar o Claustro Gótico como área de repouso, entre outros;

- Reconhecimento das escassas condições de segurança no Claustro Superior;

- O horário de maior afluência turística é das 10h30m até $13 \mathrm{~h} 00 \mathrm{~m}$;

- Os visitantes da parte da manhã são, maioritariamente, grupos de visitantes e peregrinos, contrariamente à parte da tarde, no qual predominam os visitantes individuais e as famílias. O público mais jovem visita a Sé do Porto, sobretudo, da parte da tarde.

Além disso, constatamos uma ausência de medidas de gestão, como por exemplo: a falta de informação que permita uma eficaz orientação espacial e a ausência de recomendações de itinerários distintos, tendo como finalidade evitar aglomerações nos locais mais atraentes. Adicionalmente, há uma escassez de medidas dissuasivas que evitem o impacto negativo dos turistas e a inexistência de meios de vigilância. Foi-nos revelado que o projeto de segurança contraincêndios e o alarme de intrusão foram executados e instalados, apenas, no dia 16 de julho de 2019.

Por fim, deparámo-nos que em certas áreas do conjunto catedralício possuíam determinadas "falhas", passamos a enumerar algumas: ausência de intervenções nas capelas e altares da Igreja; falta de legendagem nas peças da Sala de Tesouro e nas sepulturas escavadas na rocha e capitéis do Claustro Velho; desgaste das janelas e pavimento e pouca iluminação na Sala Capitular, entre outros.

\section{Propostas de melhoria}

A análise realizada sobre a capacidade de carga social da Sé do Porto conduziu ao desenvolvimento de um diagnóstico e a um conjunto de propostas de melhoria e trabalho, de forma que os problemas identificados possam ser resolvidos no futuro pelo gestor do espaço, neste caso o Cabido Portucalense, sendo as seguintes:

- Meios de vigilância: contratação de vigilantes ou seguranças, a fim de evitar inúmeras situações 
desagradáveis;

- Proibição do uso de flash dentro da igreja;

- Recomendação de diferentes itinerários para visitar o conjunto monumental, de modo a evitar aglomerações;

- Gestão específica de grupos organizados através da criação de um sistema de reservas prévias.

- Configuração de contadores eletrónicos para os visitantes, tendo como objetivo conhecer o número de visitantes que entram na catedral a cada trinta minutos. Isto, ajudaria a interromper temporariamente a entrada de visitantes, sem que a capacidade de carga fosse excedida.

- Sinalética direcional e de conteúdos em formato papel (flyers) ou digital (QR code com legenda iconográfica e cultural).

- Instalação de trepadores de escadas em todo complexo monumental, para possibilitar a visita a pessoas com mobilidade reduzida.

- Criação de um programa de monitorização bem constituído e regulado com listas de verificação e ferramentas simples, como relatórios simples, fotografias, entre outros, que permita o registo de problemas gerais de forma a controlar as condições físicas.

- Realização de reuniões periódicas das entidades responsáveis pela gestão dos recursos para conseguir um consenso sobre o estabelecimento de padrões quantificáveis e não quantificáveis, proporcionando uma melhor gestão do sítio.

\section{Conclusão}

Os monumentos com um elevado número de visitantes, como é o caso da Sé do Porto, devem ter em consideração a necessidade de criar medidas de gestão e regulamentação, de forma a controlar os efeitos de massificação turística. Deste modo, o conceito de capacidade de carga turística surge como um instrumento de planeamento e gestão. No domínio da gestão turística do património histórico e cultural, os estudos de capacidade de carga podem ser úteis para melhorar as condições da experiência do visitante e orientar as tomadas de decisão, tendo em conta a organização e qualidade da visita, a conservação do património, a compatibilidade de usos (cultural e religioso) e a gestão dos fluxos turísticos.

Nas últimas décadas, as investigações revelaram que as instituições culturais aplicam o conceito consoante os diferentes objetivos, como: a compatibilidade de usos, o controlo da massificação, a preservação de certos espaços patrimoniais considerados frágeis, a qualificação da visita, a procura do equilíbrio na exploração económica dos sítios, entre outros.

Com a realização desta investigação determinamos a capacidade de carga da Sé do Porto, como tal constatamos que o monumento ainda não atingiu a sua capacidade máxima de carga e aferimos a qualidade de experiência, níveis de conforto e segurança dos visitantes através dos questionários e da observação participante.

Espera-se que este estudo fomente a realização de novos estudos de capacidade de carga em recursos turísticos e patrimoniais, sugerindo assim a futuros investigadores e outros interessados por este tema que orientem para um melhor conhecimento desta realidade já existente no património cultural português. Espera-se que este trabalho permita a outros investigadores identificar as limitações dos diferentes recursos turísticos, uma vez que, a partir do momento que os recursos sejam afetados e a capacidade de carga do local seja atingida, verifica-se uma degradação dos recursos utilizados e uma perda da qualidade do produto turístico e da sua experiência turística. Consequentemente, irá existir uma diminuição dos níveis de satisfação dos turistas e um declínio nos mercados turísticos. Às entidades competentes cabe criar mecanismos de regulamentação e estratégias de gestão que, neste momento, não são alvo de qualquer ação.

\section{Referências}

ÁLVAREZ, M. P. (2010). "Evaluación de la capacidad de carga: Una herramienta para el manejo y la conservación de los sitios patrimoniales", Canto Rodado, 5: 221-247.

BONILLA, J. M. L. e BONILLA, L. M. L. (2008). “La capacidad de carga turística: Revisión crítica de un instrumento de medida de sostenibilidad", El Periplo Sustentable, 15: 123-150.

BRITO, B. R. (2017). "O Turista e o Viajante: Contributos para a conceptualização do Turismo alternativo e Responsável". Em IV Congresso Português de Sociologia, 1-17.

CEBALLOS-LASCURÁIN, H. (1996). “Tourism, ecotourism, and protected areas: the state of nature-based tourism around the world and guidelines for its development". Em IV World Congress on National Parks and Protected Areas, Reino Unido.

DÛ, F. L. (2005). La capacidad de acogida física de las Ciudades Patrimonio de la Humanidad de España. Bournemouth University.

HERNÁNDEZ, M. G. e VAQUERO, M. (2012). “Capacidad de carga en grandes recursos turístico-culturales", Anales de Geografía de la Universidad Complutense de Madrid, 32: 253-274.

JOAQUIM, G. (1997). "Da identidade à sustentabilidade ou a emergência do turismo responsável", Sociologia - Problemas e Práticas, 23: 71-100.

LÓPEZ, M. J. (2019). Turismo y patrimonio: instrumentos de gestión. Madrid, Espanha: Universidad Politécnica de Madrid.

LORENTE, P.E. (2001). “La capacidad de carga turística. Aspectos conceptuales y normas de aplicación", Anales de Geografía de la Universidad Complutense de Madrid, 21: 11-30. 
MANNING, R., WANG, B., VALLIERE, W., LAWSON, S., e NEWMAN, P. (2002). "Research to Estimate and Manage Carrying Capacity of a Tourist Attraction: A Study of Alcatraz Island", Journal of Sustainable Tourism, 10: 388-404.

OLIVEIRA, C. (2013). Caracterização do mercado de actividades de Turismo de Natureza em Portugal. Lisboa: Faculdade de Ciências e Tecnologia / Universidade Nova de Lisboa.

OMT (2005). "Gestión de la saturación turística en sitios de interés natural y cultural - Guía práctica", em E-UNWTO. https:// www.e-unwto.org/doi/pdf/10.18111/9789284407842 [consulta: 18/05/2021].

O'REILLY, A. (1986). “Tourism carrying capacity: concepts and issues", Tourism Management, 254-258.

SHELBY, B., e HEBERLTEIN, T. A. (1984). "A conceptual framework for carrying capacity determination", Leisure Sciences, 4: 433-451.

UNWTO (1981), Saturation of Tourist Destinations: Report of the Secretary General, Worl Tourism Organistion, Madrid.

UNWTO e UNEP. "Making Tourism More Sustainable - A Guide for Policy Makers", em UN Environment Document Repository. https://wedocs.unep.org/bitstream/ handle/20.500.11822/8741/-Making\%20Tourism\%20 More\%20Sustainable \%20A\%20Guide\%20for\%20Policy $\% 20$ Makers-2005445.pdf? sequence $=3 \&$ is Allowed $=y$. [consulta: $6 / 01 / 2021]$.

\section{Autor/es}

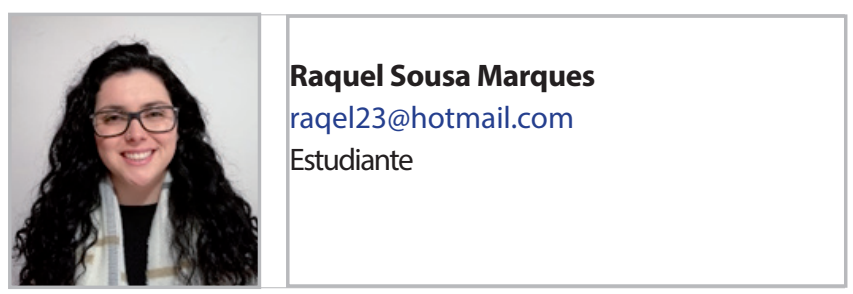

Raquel Sousa Marques. Concluiu o Mestrado integrado em Património, Artes e Turismo Cultural em 2019 pela Escola Superior de Educação do Instituto Politécnico do Porto e a Licenciatura em Arqueologia em 2017 pela Faculdade de Letras da Universidade do Porto. Atua nas áreas de Humanidades com ênfase em História e Arqueologia. 